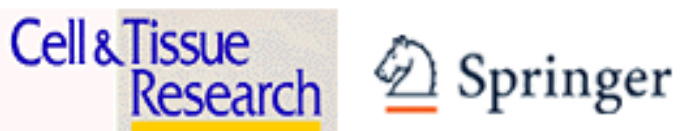

\section{The developmental roles of the extracellular matrix - beyond structure to regulation}

\begin{tabular}{|c|c|}
\hline Journal: & Cell and Tissue Research \\
\hline Manuscript ID: & CTR-09-0232.R1 \\
\hline Manuscript Type: & Special Issue Review \\
\hline $\begin{array}{r}\text { Date Submitted by the } \\
\text { Author: }\end{array}$ & \\
\hline Complete List of Authors: & $\begin{array}{l}\text { Tsang, Kwok; The University of Hong Kong, Biochemistry } \\
\text { Cheung, Martin; The University of Hong Kong, Biochemistry } \\
\text { Chan, Danny; The University of Hong Kong, Biochemistry } \\
\text { Cheah, Kathryn; University of Hong Kong, Biochemistry }\end{array}$ \\
\hline Keywords: & $\begin{array}{l}\text { extracellular matrix, development, mouse model, morphogenesis, } \\
\text { organogenesis }\end{array}$ \\
\hline
\end{tabular}

\section{(s) ScholaroNE"




\title{
The developmental roles of the extracellular matrix - beyond structure to regulation
}

\author{
Kwok Yeung Tsang, Martin C.H. Cheung, Danny Chan, Kathryn S.E. Cheah ${ }^{1,}$ \\ Department of Biochemistry and Centre for Reproduction, Development \& Growth, Li \\ Ka Shing Faculty of Medicine, The University of Hong Kong, 21 Sassoon Rd, \\ Pokfulam, , Hong Kong SAR, China. \\ ${ }^{1}$ Corresponding author
}

\begin{abstract}
Cells in multicellular organisms are surrounded by a complex three-dimensional macromolecular extracellular matrix (ECM). This matrix, traditionally thought to serve a structural function providing support and strength to cells within tissues, is increasingly recognized as having pleiotropic effects in development and growth. Elucidation of the role the ECM plays in developmental processes has been significantly advanced through studying the phenotypic and developmental consequences of specific genetic alterations of ECM components in the mouse. These studies have revealed the enormous contribution of the ECM to regulating key processes in morphogenesis and organogenesis such as cell adhesion, proliferation, specification, migration, survival and differentiation. The ECM interacts with signaling molecules and morphogens thereby modulating their activities. This review considers these advances in our understanding of the function of ECM proteins during development, going beyond their structural capacity, to embrace their new roles in intercelluar signaling.
\end{abstract}

\section{INTRODUCTION - EXTRACELLULAR MATRIX AND ANIMAL MODELS}

Structurally, the unique architecture and characteristics of tissues and organs are determined by the extracellular matrix (ECM) and the cells that produce it. ECM proteins can be classified into four general categories: collagens, structural glycoproteins, proteoglycans and elastins. Within the ECM, the components assemble into 
macromolecular superstructures such as collagen fibrils, elastic fibers and microfibrils, which interact with a plethora of other ECM proteins, such as proteoglycans and structural glycoproteins to form diverse connective tissues such as basement membranes, tendons and others. (For more details of these basic molecules and structures please refer to Box 1 and other reviews in this issue). The ECM is ancient. The existence of collagens in all metazoans including primitive sponges with simple epithelia implicates the ECM in the evolution and diversification of tissue differentiation (Aouacheria et al. 2006). It is this diversity within the ECM that produces the spectrum of structural characteristics of the different connective tissues and organs.

Gene alterations in animal model systems have revealed that specific ECM components are indispensable for development (Table 1), with roles other than for mechanical support (Fig.1). Insights into the structure and assembly of ECM proteins from various in vitro and in vivo studies have established the framework to better understand the biological function of these components in development. Interestingly, these studies demonstrated many examples of ECM involvement in signal transduction, changing our traditional view of ECM proteins as passive space fillers. The ECM undergoes constant remodeling and through its intimate interaction with cells modulates the transduction of signals that regulate differentiation, proliferation and cell death. In morphogenesis and organogenesis, the ECM integrates spatio-temporal cues in a three-dimensional structure involving multiple cell types. In vivo studies of defined alterations of ECM components in animal model systems are an important means to better understanding of ECM function. Over the last two decades, researchers have used complementary model organisms to study genes and signaling pathways in specific developmental processes. Nematode worms (Caenorhabditis elegans), fruit flies (various Drosophilia species), zebrafish (Danio rerio), frogs (Xenopus laevis and tropicalis), chicken (Gallus gallus) and mouse (Mus musculus) have all contributed significantly to our knowledge of ECM gene function. Each model organism has distinct attributes in the study of a developmental process or for a certain genetic manipulation, often with surprising findings such as unexpected genetic interaction or redundancy. 
In the mouse, recent technical advances in the conditional manipulation of genes using a drug-inducible Cre-loxP system not only provided a means to overcome the problem of embryonic lethality, but also allowed researchers to address cell/tissue-specific functions of ECM genes at selected stages of development and growth. Important lessons and new paradigms are emerging from these studies, which provide new insights into the importance of cell-ECM interactions and the role of the ECM in modulating signaling during tissue morphogenesis and development. A recent review provided an excellent overview of ECM function derived from studies in mouse models with alterations in various ECM proteins (Aszodi et al. 2006). In this review, we will discuss recent advances in our understanding of the roles of ECM proteins in modulating signaling activities for proper progression of developmental processes, in addition to their "traditional" structural roles.

\section{DEVELOPMENT DEPENDS ON THE STRUCTURAL INTEGRITY OF THE $\underline{\mathbf{E C M}}$}

The ECM is crucial even before fertilization takes place. The zona pellucida of mouse oocyte, a thick matrix made of three glycoproteins ZP1, ZP2 and ZP3, is indispensable for oocyte maturation and fertilization (Wassarman et al. 2004;Monne et al. 2008). During the course of development, ECM composition and organization are strictly regulated and modified to modulate tissue morphogenesis and organogenesis; abnormalities in the ECM often lead to developmental defects and/or lethality (Table 1).

\section{Early embryonic development requires a proper basement membrane}

The basement membrane (BM) is a specialized sheet of ECM containing many proteins and glycosaminoglycans including laminin, collagen IV and heparan sulfate proteoglycan (HSPG). It provides structural support, acts as a selective barrier and modulates signaling cues for adjacent cells (see also Box 1). It is first synthesized in the peri-implantation mouse embryo at the blastocyst stage, by the primitive endoderm and trophectoderm. Laminin-111 $(\alpha 1 \beta 1 \gamma 1)$ and laminin-511 $(\alpha 5 \beta 1 \gamma 1)$ are the earliest isoforms found in embryonic BM, and absence of both resulted in early lethality of mouse embryos with defects in primitive endoderm differentiation and epiblast polarization (Miner et al. 
2004;Smyth et al. 1999). The embryonic BM may also prevent the epiblast from differentiating precociously into mesoderm-like cells as occurs in embryoid bodies derived from embryonic stem cells of Lamcl $^{-/-}$embryos (Fujiwara et al. 2007). Nevertheless, laminin-111 and laminin-511 can partially compensate for each other, since embryos lacking either laminin-511 or laminin-111, survive longer (Miner et al. 1998; Miner et al. 2004). In the absence of laminin-111, Lamal $^{-/-}$embryos do not form a proper Reichert's membrane, a BM that separates embryonic and maternal tissues, and cannot initiate gastrulation resulting in lethality (Miner et al. 2004) (Table 1). By contrast, Lama $^{-/-}$embryos deficient in laminin-511 undergo gastrulation but develop severe defects in multiple organs (Miner et al. 1998;Miner et al. 2004). Thus laminin $\alpha 1$ and $\alpha 5$ chains have overlapping and also independent roles in multiple developmental processes (further discussion to follow).

Perlecan is a ubiquitous and multifunctional HSPG found in BM (Whitelock et al. 2008). Hspg2-/- embryos that lack perlecan show a complex phenotype, with about half the embryos dying at around $10.5 \mathrm{dpc}$ from defective myocardial BM (Costell et al. 1999;Arikawa-Hirasawa et al. 1999). Interestingly, mice expressing perlecan with a reduced number of heparan sulfate side chains are viable and fertile, but have small eyes and postnatal lens degeneration (Rossi et al. 2003), suggesting that the core protein itself play an important role in the ECM or that the side chains share redundant functions.

Collagen IV is another major component of the BM and also the embryonic vasculature (Poschl et al. 2004) and is absolutely required for their structural stability and integrity . While laminins can initiate BM assembly at peri-implantation stages in the absence of collagen IV (Miner et al. 2004;Smyth et al. 1999;Poschl et al. 2004), the latter is required for conferring barrier functions and maintaining BM integrity associated with increasing mechanical demand as the embryos grow (Poschl et al. 2004). Interestingly, mouse embryos lacking HSP47, a molecular chaperone that specifically assists collagen folding in the endoplasmic reticulum (ER), exhibit disrupted BM structures associated with aberrant collagen IV synthesis (Nagai et al. 2000). Similarly, defective collagen IV assembly, disruption of BMs and embryonic lethality are also observed in mice lacking 
the collagen modification enzymes proline 4-hydroxylase $\alpha 1$ (encoded by P4hal) or lysyl hydroxylase 1 (Plod1) (Holster et al. 2007; Rautavuoma et al. 2004;Ruotsalainen et al. 2006), highlighting the intracellular synthesis and processing of collagens is crucial for secreting quality triple helix ready for proper ECM assembly, which ultimately determines the fate of the developing embryos. In humans, prolyl 3-hydroxylase 2 has recently been found to be important for modifying collagen IV of the BM in vitro (Tiainen et al. 2008)\}; whether this enzyme has an influence on early embryonic development remains to be tested in a knock-out mouse model.

These and other studies demonstrate that embryonic development requires a well-defined BM. Moreover, recurrent use of these (and other) BM components in different anatomical sites implies subtle structural variations of the ECM may be pivotal in generating diverse tissue forms of an organism.

\section{Tissue characteristics relies on collagen fibrillogenesis}

As organogenesis begins increasing complexity of tissue development requires diversified structural support which cannot be provided by a basement membrane alone. In tissues/organs such as tendon, bone, cartilage and skin, the structural strength is contributed mainly by collagen fibrils composed of fibrillar collagens, including collagens I, III and V (in most tissues) and collagens II and XI (in cartilage and the vitreous humour). Collagen fibrillogenesis is a multi-step process involving the assembly of individual collagen molecules into an intermediate form which then undergoes lateral and linear growth to become the mature fibril (Kadler et al. 2008). ECM molecules, including fibronectin and small leucine-rich proteoglycans (SLRPs) such as decorin, biglycan, fibromodulin, and lumican, regulate fibrillogenesis. For example, corneal collagen fibrils do not undergo lateral growth but maintain a lumican-dependent homogeneous distribution of small-diameter fibrils to favour transparency (Chakravarti et al. 2006). In contrast, in tendon, fibromodulin promotes the maturation of small-diameter fibril intermediates (Ameye et al. 2002) into densely packed thick fiber bundles organized hierarchically to provide high tensile strength and transmit forces (Banos et al. 2008). In the dermis, heterotypic collagen fibrils containing mainly collagens I, III and V 
are the major structural components responsible for its characteristic strength and resilience. Defective fibrillogenesis can lead to severe skin abnormalities. Haploinsufficiency for the Col5al allele in mice results in impaired fibril nucleation and growth, leading to hyperextensible skin with reduced tensile strength resembling human Ehlers-Danlos syndrome (Wenstrup et al. 2006). Although collagen V is a quantitatively minor fibrillar collagen, this example emphasizes gene dosage is an important parameter for fibrillogenesis and indicates strict genetic control of proper ECM assembly during development. Fibrillogenesis in skin is also fine-tuned by the SLRPs decorin and lumican which limit lateral growth of the fibril; mice lacking either of them have increased fibril diameter in the dermis and fragile skin (Chakravarti et al. 1998;Danielson et al. 1997) (Table 1). In the heart, fibrillar collagens have been implicated in ventricular myocardial morphogenesis and heart valve development (Peacock et al. 2008), as shown in fetal mice deficient in collagens V and XI (Lincoln et al. 2006). Therefore, tissue development and function relies on a structurally integral ECM formed by proper assembly of its components.

\section{$\underline{\text { ECM elasticity/stiffness influences cellular differentiation }}$}

The rigidity of a tissue depends on the composition of its ECM. Bone is most stiff because of the extensive highly crosslinked collagen fibrils and matrix mineralization. Aorta, lung and skin can withstand repeated stretching because of the presence of elastic fibers (Wagenseil and Mecham 2007). Recently, variation in ECM rigidity has been proposed to have additional important roles, such as directing stem cell lineage specification (Engler et al. 2006) and regulating the continuous beating of cardiomyocytes in culture (Engler et al. 2008). Mesenchymal stem cells grown on soft gel differentiated into a neuronal-like lineage but when grown on a stiff gel differentiated into the osteoblast lineage; gels of intermediate stiffness stimulated the cells to take on a myoblast phenotype (Engler et al. 2006). The elasticity of the ECM acts in concert with cytoskeletal tension to regulate the release of soluble factors from the ECM, such as the release of TGF $\beta$ from integrin-bound latent TGF $\beta$ binding protein-1 (LTBP1) (Fig.1b); these factors then mediate cellular responses to direct cell fate specification, tissue 
remodeling and various developmental processes (Fontana et al. 2005; Wells and Discher 2008;Akimov and Belkin 2001).

\section{DEVELOPMENTAL PROCESSES ARE REGULATED BY ECM COMPONENTS}

In the developing vertebrates the complex three-dimensional network of the ECM not only provides structural strength and integrity to various organs and tissues but also plays important functional roles in interacting with numerous growth factors and signaling molecules to regulate cellular events such as cell adhesion, proliferation, specification, migration, survival and differentiation. The following section will highlight some of the events mediated by the ECM as manifested in several developmental processes.

\section{$\underline{\text { Role of the ECM in Neural Crest Cell migration }}$}

Proper control of cell migration is essential for directing cells to their appropriate destinations where they can differentiate into their target tissues during morphogenesis and the ECM provides the substratum on which this migration occurs. The neural crest of the vertebrate embryo, with its extensive migratory behavior and multipotency, has been one of the most powerful systems for the study of the role of the ECM in controlling cell migration, adhesion, differentiation and growth. Neural crest cells arise from the dorsal tip of the neural tube and undergo an epithelial to mesenchymal transition (EMT) during delamination, then migrate along a stereotypical pathway to their destinations to generate many cell types throughout the whole embryo, notably neurons and glia of the peripheral and autonomic nervous system, the craniofacial skeleton, and skin melanocytes (Le Douarin 2001).

Most of the major ECM components are found in the interstitial and/or basement membrane along neural crest cell migratory routes (Newgreen and Thiery 1980;Krotoski and Bronner-Fraser 1986;Perris et al. 1991;Tucker and McKay 1991). The spatial and temporal composition of the ECM provides both permissive and non-permissive guidance cues for neural crest migration. Several matrix glycoproteins have been shown to 
promote neural crest migration in vitro or in vivo in chick embryos, including fibronectin (Duband et al. 1986;Newgreen 1989), laminin (Duband and Thiery 1987), collagen I and IV (Perris et al. 1993a;Perris et al. 1993b) and tenascin (Bronner-Fraser 1988; Tan et al. 1987), whereas aggrecan, versican (Landolt et al. 1995;Perris et al. 1996) and collagen IX (Ring et al. 1996) prevent the attachment and migration of neural crest cells. In contrast, functional ablation of some of these ECM components in mice does not significantly affect neural crest development, perhaps because compensation by other matrix molecules or subtype isoforms masks the phenotype. One exception is laminin- $\alpha 5$ knockout mice which show defects in neural crest migration and delay in gangliogenesis of the peripheral ganglia, suggesting a requirement of laminin- $\alpha 5$ chain for proper neural crest migration and timely differentiation (Coles et al. 2006).

The ability of the ECM components to promote or inhibit neural crest migration is highly dependent on their native macromolecular structure and composition. The cell surface integrin family of receptors plays a predominant role in mediating neural crest migration through interaction with ECM molecules. Distinct mechanisms deployed by cranial and trunk neural crest cells in integrin regulation appear to confer their differential migratory behavior and cell fate in response to variations in substratum composition along the anterior-posterior axis (Lallier et al. 1992;Strachan and Condic 2003). The presence of various integrin isoforms affects their ability to interact with specific matrix molecules to elicit downstream cellular events controlling adhesion, migration, proliferation and survival (Delannet et al. 1994; Testaz and Duband 2001).

Recent studies in Xenopus embryos demonstrated that Syndecan-4, a cell surface HSPG that may serve as an ECM receptor, acts in a coordinated manner with planar cell polarity to control the directional migration of neural crest cells through regulating the activity of small GTPases (Matthews et al. 2008). In addition, fibronectin has been shown to promote neural crest differentiation along the smooth muscle lineage (Costa-Silva et al. 2009). 


\section{ECM organization and remodeling is required for notochord development}

The notochord is an embryonic midline structure that plays an essential patterning role in development sending signals to the surrounding tissues with key roles in specifying ventral fates in the central nervous system as well as controlling left-right asymmetry [reviewed in (Stemple 2005)]. The notochord also plays an important structural role acting as the early axial skeleton of the embryo until the vertebrae form. Later in development the notochord contributes to the centre of the intervertebral discs in a structure called the nucleus pulposus. The notochord has also been proposed to participate in the segmental patterning of the vertebral column, where the vertebral bodies arise by secretion of cartilage matrix from the condensed mesenchyme surrounding the notochord. Notochordderived signals are critical for induction and patterning of the sclerotome which gives rise to the vertebral body. Notochordal cells are surrounded by a rich ECM sheath composed of collagen II, IX and XI, perlecan and fibronectin, (Gotz et al. 1995;Hayes et al. 2001). Structural defects in the notochord may also impact on its function as a signaling centre to pattern surrounding tissues. Consistent with a key role of the ECM for notochord function, inactivation of Col2al, which encodes the $\alpha 1$ (II) chain required for collagens II and XI assembly, results in persistence of the notochord and defects in intervertebral disc formation (Li et al. 1995a;Aszodi et al. 1998). Type II collagen is therefore essential for proper remodeling of the notochord and formation of the intervertebral disc.

Several of the genes encoding these ECM components are directly regulated by the SOX transcription factors, SOX9, SOX5 and SOX6. SOX9 is required for maintaining the structural integrity of the notochord. The formation of the notochord sheath appears to be governed by SOX5 and SOX6, (Smits and Lefebvre 2003). Genetic ablation of both Sox5 and Sox6 in the mouse revealed that these genes play an important role in notochord development. Sox5 and Sox6 transcripts co-localize in notochord cells and surrounding sclerotome-derived cells. In Sox5/Sox6 double mutants, the notochord is still generated but expression of genes encoding ECM components such Col2al, Agc and Hspg2 are severely downregulated, resulting in lack of ECM sheath formation. The mutant notochord cells subsequently undergo apoptosis and the development of vertebral bodies is impaired (Smits and Lefebvre 2003). Similarly in Sox9 null embryos, although a 
notochord is established, it disintegrates after E9.5, and ECM genes which are SOX9transcriptional targets including Col2al (Bell et al. 1997) and aggrecan (Acan) (Han and Lefebvre 2008b), are not expressed (Barrionuevo et al. 2006). These functions of the notochord are likely mediated via cell-matrix interactions involving cell surface receptors such as integrins and fibronectin. Fibronectin null mutants lack a notochord (George et al. 1993) $\alpha 5 \beta 1$ integrin mediates cell-ECM interactions with fibronectin. In $\alpha 5$ integrin null mutants notochordal structure is not maintained resulting in loss of notochordal signals (Goh et al. 1997). Comparisons between the phenotypic and molecular impact of mutations in these Sox mutants with those arising from loss of function of the individual ECM genes should also provide valuable insight into which combinations of ECM proteins work together and are essential for tissue function.

\section{ECM regulation of cartilage development}

During development, cartilage forms the template for subsequent bone growth in the process of endochondral ossification, in which mesenchymal condensation is followed by chondrocyte differentiation, proliferation and hypertrophy (Kronenberg 2003). Cartilage is rich in ECM; and not surprisingly, the expression of cartilage ECM genes is under strict genetic control mediated by instructive signals and transcription factors. The critical roles of many ECM proteins such as collagen II, collagen XI, aggrecan, perlecan, link protein as components of the cartilage ECM, is reflected in the severe skeletal malformation that arises in their absence (Costell et al. 1999;Arikawa-Hirasawa et al. 1999; Watanabe and Yamada 1999;Li et al. 1995b;Li et al. 1995a;Watanabe et al. 1994;Li et al. 2001). SOX proteins play a critical role in directing the biosynthesis of a functional cartilage ECM since many of these genes regulated by these SOX factors. Genetic ablation of SOX9 and its partners SOX5 and SOX6, during chondrogenesis results in severe defects in chondrocyte differentiation, ECM production and consequently endochondral bone formation (Akiyama et al. 2002)(Smits et al. 2001). In Sox9 null mutants mesenchymal cells fail to condense, chondrocytes fail to differentiate and ECM gene targets Col2a1, Col9a2, Col11a2 and Acan (Lefebvre et al. 1997;Bridgewater et al. 2003; Han and Lefebvre 2008a;Bell et al. 1997), are not expressed (Bi et al 1999). Mutations in each of the ECM genes regulated by SOX9 have been shown to impact on 
cartilage development and are less severe ( $\mathrm{Li}$ et al. 1995b; Li et al. 1995a;Watanabe et al. 1994; Li et al. 2001). However as illustrated by the Col2al and Acan mouse mutants the final phenotype that arises is a consequence of more than the impact of the individual mutant ECM protein but rather the abnormal ECM that arises from the downstream effects on other components (Wai et al. 1998;So et al. 2001;Aszodi et al. 1998). The molecular consequence of loss of Sox9 function also highlights the critical role of the ECM for chondrogenesis and reveals the collective contribution of multiple ECM components.

This ECM supports chondrocyte adhesion and proliferation through binding to the cell surface adhesion molecule $\beta 1$ integrin (Aszodi et al. 2003). The ECM also integrates several signaling pathways. Cartilage ECM regulates fibroblast growth factor (FGF) signaling (Arikawa-Hirasawa et al. 1999) and the diffusion of the morphogen ligand Indian hedgehog (IHH) (Cortes et al. 2009) (Fig.1a and Table 1) which coordinates the cartilage-to-bone transition through regulating the differentiation of collagen $\mathrm{X}$ expressing hypertrophic chondrocytes and collagen I-expressing osteoblast ( $\mathrm{Hu}$ et al. 2005; Rodda and McMahon 2006). Bone morphogenetic protein (BMP) signaling and its regulation of downstream targets such as $\mathrm{SOX} 9$, also plays a crucial role in this process. Cartilage development is severely compromised in BMP receptor null mutants (Yoon et al. 2005). Thus, a complex genetic network dictates ECM gene expression and organization, which in turn regulates the signaling pathways to coordinate the process of cartilage and bone formation.

\section{Organizing developmental cascades at the neuromuscular junction}

The neuromuscular junction (NMJ) is a specialized synapse between a motor neuron and an effector muscle fiber for controlling muscle contraction. Recent studies employing multiple mouse models indicate that differentiation of the NMJ depends on the cooperation of extracellular organizers including both the signaling and ECM modules, and they act in a coordinated manner to exert both cell-type and stage-specific effects. Motor neuronal fibroblast growth factor (FGF) 7/10/22 signaling via their receptor FGFR2b and the collagen $\alpha 2(\mathrm{IV})$ chain contribute to pre-synaptic vesicle clustering 
during embryonic NMJ formation while laminins $\alpha 4, \alpha 5, \beta 2$ subunits are required for pre- and post-synaptic maturation in postnatal period. Post-weaning maintenance of NMJ is mediated by collagen IV isoform (Fox et al. 2007;Nishimune et al. 2008). Other stagespecific ECM organizers including laminin-211, perlecan and agrin cooperatively mediate acetylcholine receptor clustering on the postsynaptic membrane (Smirnov et al. 2005) (Table 1), a process which is also critical for NMJ maturation and is further finetuned by WNT3 signaling both in vitro and in vivo (Wang et al. 2008a;Henriquez et al. 2008). In addition, myelination of peripheral axons by Schwann cells is a process that requires laminin $\gamma 1$ chain (Chen and Strickland 2003; Yu et al. 2005)(Table 1).

\section{Epithelial-mesenchymal crosstalk: integration of ECM and morphogen signals}

A reciprocal interaction between adjacent epithelial and mesenchymal tissues represents a recurrent mechanism in embryonic tissue morphogenesis and organogenesis. The two compartments generate and receive signals from each other to propagate morphogenesis through regulating cellular proliferation, differentiation and survival. Given the diverse tissue forms and functions that can be generated by epithelial-mesenchymal crosstalk, somewhat surprisingly, the major signaling pathways including BMP, FGF, WNT, Hedgehog and growth factors such as platelet-derived growth factor (PDGF), are recurrently employed to direct tissue-specific gene expression and morphogenesis. Recent findings indicate that ECM molecules also participate in the crosstalk by directly transducing signals through binding with cell surface receptor such as integrin, and this participation is essential for developmental process.

\section{Laminin $\alpha 5$ chain promotes hair follicle development}

Hair follicle morphogenesis begins at $14.5 \mathrm{dpc}$ with the downward invagination of the skin epidermis into the underlying dermis to form a hair placode. This process is dependent on reciprocal signaling between the epidermis (of undifferentiated keratinocytes) and the underlying mesenchymal condensate which will become the dermal papilla. This papilla will develop into a signaling center to support hair follicle development and to regulate hair production. It has been recently shown that lamininintegrin interaction in the epidermal BM is required for maintenance of the dermal papilla 
and hair follicle downgrowth (Gao et al. 2008). Consistently, in mice lacking integrinlinked kinase (ILK; linking integrin to cytoskeleton) in keratinocytes, hair follicle development is severely impaired at a very early stage (Nakrieko et al. 2008). Laminin511 is absolutely required for hair follicle development (Li et al. 2003) through binding to $\beta 1$ integrin on mesenchymal cells, consequently induces primary cilia formation to receive PDGF and SHH from the epidermal cells. The mesenchymal cells also express and secrete Noggin to inhibit BMP signaling in the epidermal cells. Such an inhibition is required to facilitate canonical WNT signaling to promote $\mathrm{SHH}$ secretion to the dermal papilla mesenchyme, thus forming a positive feedback loop to support hair follicle development (Gao et al. 2008). Laminin-511, therefore, plays a key role in initiating a complex signaling crosstalk between the epithelium and the mesenchyme that lead to hair morphogenesis (Fig. 1d).

\section{Branching morphogenesis of submandibular salivary gland, lung and kidney}

Branching is an important patterning process required for the development of many vertebrate organs, including the submandibular salivary gland (SMG), lung and kidney. The branching structure is generated by repetitive bifurcations of epithelial outgrowths mainly regulated by epithelial-mesenchymal crosstalk.

In SMG branching morphogenesis, a crosstalk scenario between morphogens and laminins is emerging. SMG development begins at around $11.5 \mathrm{dpc}$, when the epithelium under the tongue starts thickening to form a bud which then undergoes successive rounds of expansion and branching to form multiple cords and buds (Hoffman et al. 2002;Sakai et al. 2003). FGFR2b expressed in branching epithelium and its corresponding ligand FGF10 (and to a lesser extent with FGF8) in the mesenchyme are indispensable for SMG development, stimulating bud elongation and epithelial cell proliferation in addition to branching (Steinberg et al. 2005;Jaskoll et al. 2004b) (Min et al. 1998;Sekine et al. 1999;Entesarian et al. 2005) (Jaskoll et al. 2004b;De et al. 2000;Jaskoll et al. 2005). Both laminin $\alpha 1$ and $\alpha 5$ chains are present in the BM of the developing epithelium and the latter is required for branching and lumen formation (Rebustini et al. 2007). The function of laminin $\alpha 5$ is most likely mediated through integrins $\alpha 3 \beta 1$ and $\alpha 6 \beta 1$, since blockage 
of $\beta 1$ integrin binding or embryos lacking both integrin $\alpha 3$ and $\alpha 6$ display similar phenotypes (Rebustini et al. 2007). Importantly, reduced expression of Fgfr1, Fgfr2b and Fgf1 is observed in Lama5 $^{-/-}$SMG , suggesting that laminin $\alpha 5$ and FGFs may form a positive feedback loop to promote SMG development (Rebustini et al. 2007). Moreover, PDGF induces expression of FGF1, 3, 7 and 10 in mesenchyme (Yamamoto et al. 2008). SHH (Jaskoll et al. 2004a;Hashizume and Hieda 2006), BMP7 (Hoffman et al. 2002; Jaskoll et al. 2002) and epidermal growth factor (EGF) (Jaskoll and Melnick 1999) signaling are also implicated in SMG branching morphogenesis, although there is as yet no evidence of crosstalk among these pathways.

The bronchial tree network in mammalian lung is the end product of repetitive branching operations which were recently classified into three genetically programmed branching modes (Metzger et al. 2008). FGF10-FGFR2b epithelial-mesenchymal signaling is again a central component for lung branching and also lung bud formation from the ventral side of foregut endoderm (reviewed in (Cardoso and Lu 2006)). FgflO is expressed in the distal mesenchyme and Fgfr2b is expressed throughout the lung epithelium (Cardoso and Lu 2006). Similar to early hair follicle and SMG development, BMP4, SHH and WNT7b signaling are also implicated in early lung branching morphogenesis (Cardoso and Lu 2006) but ECM involvement has not been shown in vivo. In vitro functional blocking experiments showed that antibodies against laminin-111, $\beta 1$ chain or $\gamma 1$ chain interfered with branching in lung bud explants (Schuger et al. 1990a;Schuger et al. 1990b;Schuger et al. 1991). Since mouse embryos lacking any one of the laminin-111 chains die before lung bud formation, the effect of laminin-111 on lung branching need to be addressed with conditional-null mutants. In comparison, Lama5 $^{-/-}$and Lama5 conditional-null mutants display lung abnormalities such as defective lobar septation and epithelial cell differentiation without affecting branching, indicating tissue-specific functions of different laminin isoforms (Nguyen et al. 2002;Nguyen et al. 2005).

Mammalian metanephric kidney forms through reciprocal signaling between the ureteric bud epithelium and the metanephric mesenchyme (Yu et al. 2004). Glial cell line-derived neurotrophic factor (GDNF) expressed in the mesenchyme and its cognate receptor RET 
in the epithelium mediate a key signal in the initiation of uteric bud formation in the Wolffian duct and outgrowth into the adjacent metanephric mesenchyme (Costantini and Shakya 2006). Subsequently, feedback signaling between GDNF and Wnt11 expressed in the epithelial tips regulates branching morphogenesis (Majumdar et al. 2003). These processes are dependent on Gremlin 1-mediated inhibition of BMP4 signaling in the metanephric mesenchyme (Michos et al. 2007). In Grem1-null mice showing increased BMP signaling, Gdnf and Wnt11 expression is downregulated and uteric bud outgrowth is blocked, resulting in bilateral kidney agenesis (Michos et al. 2004;Michos et al. 2007). Interestingly, mice deficient in the ECM molecule nephronectin (expressed by uteric bud epithelium) or its receptor integrin $\alpha 8$ (expressed in metanephric mesenchyme) also displayed reduced Gdnf expression and kidney agenesis (Linton et al. 2007). Whether nephronectin interacts with gremlin 1/BMP4 and regulates BMP signaling in branching morphogenesis remains to be determined, and it is likely that additional ECM molecule(s) share redundant role with nephronectin in kidney organogenesis (Linton et al. 2007) (Table 1).

Understanding how differential composition of the ECM contributes to the activities of the major signaling pathways will deepen our knowledge of how tissue morphogenesis and organogenesis is accomplished with the recurrent use of the same sets of signaling mechanism in a tissue-specific manner. Such information will be invaluable for tissue engineering technology to construct tailor-made organs for regenerative medicine.

\section{THE ECM MODULATES MORPHOGEN TRANSPORT AND AVAILABILITY}

In addition to acting as structural components and sending signals directly to cells through cell surface receptors, accumulating evidence shows that the ECM can also physically interact with signaling molecules and their regulators so as to modulate their availability, signaling range and binding affinity, thus providing additional levels of regulation for fine-tuning signals from different pathways.

\section{Sequestration and movement of FGF in the ECM}


The range that signals can cover is an important theme for the major classes of morphogen ligands, including BMPs, FGFs, WNTs and Hedgehogs, but how gradients of morphogen concentration and activity are established to give precise developmental/patterning instructions is still not fully understood. A balance of production, activation/inactivation and degradation (through endocytosis) of the ligands and regulators in the extracellular space may constitute part of the mechanism (Akiyama et al. 2008). Another part could be the regulation of macromolecular movements in the extracellular space through an affinity with ECM components. HSPGs are common modulators, which may be membrane tethered (e.g. glypican and syndecan) or ECM bound (e.g. perlecan). They play an essential role in FGF signaling for directly stabilizing FGF-FGFR binding (Ornitz 2000). Variations in the composition of heparan sulfate side chain of HSPGs confer affinities for different FGFs: for example, L-iduronic acid residues favour binding to FGF2 but not FGF10 (Jia et al. 2009). Moreover, a recently identified mutation in mouse, $F g f 9^{\text {Eks/+ }}$, provides in vivo evidence that the high affinity of FGF for HSPG restricts their diffusion range in the ECM: reduced affinity of FGF9 with HSPG in this mutant results in increased FGF9 signaling range and consequently joint fusion and cranial synostosis (Harada et al. 2009; Murakami et al. 2002). Perlecan is a known modulator of FGF movement and/or storage in the ECM. It can bind to FGF9 (Melrose et al. 2006), to FGF2 in cartilage (Smith et al. 2007a) and in the lens capsule of the eye (Tholozan et al. 2007), to FGF18 in cartilage (Smith et al. 2007b) and to FGF10 in the BM of the SMG (Patel et al. 2007). Proteolytic release of FGF2 and FGF10 from perlecan activates FGFR and MAPK signaling in ex vivo culture of lens capsule and SMG, respectively (Tholozan et al. 2007; Patel et al. 2007), but whether and how these cleavage events are regulated to release the ligand in a timely manner is not known. Perlecan is proposed to be a reservoir for morphogens and growth factors: it is estimated one perlecan molecule can bind with a maximum of 123 molecules of FGF2 in vitro (Smith et al. 2007a). The number is likely to be smaller in vivo, since perlecan can also interact with many different signaling molecules. How these different and potentially competing interactions between ECM and signaling molecules are modulated in development is an important and challenging area of research for the future. 


\section{ECM-mediated fine tuning of BMP signaling}

The strength and range of morphogens must be tightly regulated for proper morphogenesis to occur and cell surface receptors and the ECM have been implicated in shaping the extracellular morphogen gradient by influencing their spreading. One of the most characterized signaling gradients is that of BMP which is essential for development and is crucial for morphogenesis in most if not all tissues. Its regulatory network has evolved into a stunning system comprising a plethora of intracellular and extracellular components differentially expressed in a tissue-specific manner to modulate the range and strength of signaling. Gastrulating Xenopus embryos serve as an outstanding model to illustrate how different members of the BMP family and their regulators, such as Chordin, Noggin, Twisted Gastrulation (TSG) and Crossveinless-2 (CV2), control dorsoventral patterning (Ambrosio et al. 2008;Bier 2008). In mouse skeletogenesis, CV2 and TSG cooperate to establish a BMP morphogenetic field in the developing vertebral/intervertebral regions, probably by concentrating TSG/BMP4 complexes in the vertebral body cartilage (Zakin et al. 2008; Ikeya et al. 2008).

BMPs exhibit direct affinity for intact ECM proteins such as structural collagens. A conserved BMP-binding domain has been identified in both invertebrate and vertebrate genes encoding collagen IV chains (Wang et al. 2008b). Studies in the Drosophila embryo have suggested that binding of a Dpp/Scw heterodimer (the orthologs of BMP) to collagen IV facilitates the assembly of an inhibitory complex in the presence of Sog (the ortholog of Chordin) thereby decreasing BMP signaling activity, whereas in the absence of Sog, collagen IV promotes Dpp/Scw-receptor interactions leading to activation of the BMP signaling pathway. BMP also interacts with procollagen IIA via its cysteine-rich domain, (Larrain et al. 2000;Zhu et al. 1999). Previous studies demonstrated that overexpressing procollagen IIA induces a secondary body axis in Xenopus embryos, suggesting a role as a BMP antagonist (Larrain et al. 2000). In contrast, studies in IIAnull mice revealed that procollagen IIA probably facilitates BMP signaling during heart development [(Cheah et al. 2005) and Wong, Cheah unpublished data]. Therefore, the effect of collagens IIA and IV on BMP signaling are most likely context-dependent. It is a challenging task to determine whether collagen IIA and IV and other BMP binding 
proteins co-localize during development and can interact with each other or with other ECM proteins to regulate BMP signaling in vivo. BMP signaling is essential for inner ear development (Pujades et al. 2006; Li et al. 2005;Chang et al. 2008a) where SOX9 and collagen II are expressed in the sensory and nonsensory epithelia of the developing inner ear (that contain BMs and collagen IV) (Mak et al. 2009; Khetarpal et al. 1994;Chang et al. 2008b;Lui et al. 1995). Thus it is an interesting anatomical site to test whether the ECM components interact and modulate BMP signaling.

Fibrillins also exhibit affinity for BMP as well as TGF $\beta$ and regulate their bioavailability (Ramirez and Sakai 2009). Fibrillins are large cysteine-rich glycoproteins that constitute the backbone of microfibrils that may or may not be associated with elastic fibers. BMPs can be targeted directly to microfibrils through non-covalent interactions between their pro-domains and the N-terminal of fibrillin-1 and fibrillin-2 (Sengle et al. 2008). Genetic interaction between fibrillin-2 and BMP7 is important in limb digit patterning (ArteagaSolis et al. 2001), consistent with the co-localization of BMP7 with both fibrillin-1 and -2 in the developing limb (Sengle et al. 2008). Thus it is likely that fibrillins differentially regulate BMP signaling in a context-dependent manner, as do the collagens.

Mammalian BMP signaling must be tightly regulated to prevent undesirable induction of chondrocytic/osteoblastic differentiation that leads to ectopic bone formation and ECM mineralization. Such a regulation may be mediated by matrix Gla protein (MGP), an ECM protein which is expressed by vascular smooth muscle cells (VSMCs), endothelial cells and chondrocytes; mice lacking MGP display ectopic mineralization in arteries and growth plate cartilage and die of arterial rupture (Luo et al. 1997). MGP can inhibit BMP2 and BMP4 signaling through direct binding (Yao et al. 2006; Yao et al. 2008). Intriguingly, expression of MGP (and VEGF) in cultured bovine aortic endothelial cells was indirectly induced by BMP2 and BMP4 in a TGF $\beta / A L K 1-d e p e n d e n t$ manner, suggesting a regulatory negative feedback loop controls the level of BMP activity to facilitate angiogenesis while preventing vascular mineralization (Yao et al. 2006). Overexpressing MGP in lung impaired BMP4 expression and subsequent signaling, resulting in defects in pulmonary vascular development (Yao et al. 2007). However, 
whether the arterial mineralization in MGP null mice is due to enhanced BMP signaling remains to be determined. Nonetheless, these observations suggest that BMPs not only interact with the ECM but can also regulate the activities of ECM components, a flexible strategy for fine tuning signaling range and strength to accommodate changing developmental requirements.

\section{ECM PROVIDES THE MICROENVIRONMENT FOR STEM/PROGENITOR}

\section{CELLS}

Stem cells are characterized by their ability to self-renew and differentiate into different specialized cell types, thus playing important roles in development and tissue maintenance. The potential of neural stem cells to treat various neurological diseases has been the focus of studies in recent years aiming to understand the factors both extrinsically and intrinsically involved in controlling their maintenance, proliferation and differentiation into one of the three cell types of the central nervous system (CNS): neurons, astrocytes and oligodendrocytes. Multipotent neural stem cells have been isolated from several regions of the CNS including the subventricular zone (Reynolds and Weiss, 1992), the hippocampus (Kukekov et al. 1999), the cerebellum (Laywell et al. 2000) and the spinal cord (Kalyani et al. 1997;Laywell et al. 1999). The proliferative and differentiation capacity of neural stem cells in each region is thought to be determined by the factors present in their surrounding environments, termed their "niche", including growth factors and the ECM (Fig. 1c). Laminin and fibronectin are two important ECM molecules secreted by cells in the niche and have been implicated in neural stem cell growth, differentiation and migration (Flanagan et al. 2006; Novak and Kaye 2000). These proteins function as a permissive substrate in promoting proliferation and differentiation of mouse neuroepithelial cells (Drago et al. 1991) and migration of cerebellar neural precursor cells in vitro (Kearns et al. 2003), as well as migration of neural precursors through the mouse rostral migratory stream in vivo (Murase and Horwitz 2002). Several in vitro studies indicate a critical role of $\beta 1$-integrin signaling in mediating the effects of the ECM on neural stem cells in a timely and spatially controlled manner. In a model system of neurosphere cell cultures, genetic ablation of $\beta 1$-integrin function resulted in reduced neural progenitor proliferation and increased cell death, as 
well as impairment of cell migration on different ECM substrates, suggesting a crucial role of $\beta 1$-integrin-mediated cell-ECM interaction in the regulation of progenitor cell proliferation, survival and migration (Andressen et al. 1998; Leone et al. 2005).

Chondroitin sulfate proteoglycans (CSPGs) are also present in the microenvironment of neural stem cells both during development and in the adult neural stem cell niche (Sugahara and Mikami 2007). Treatment of neurospheres or telencephalic ventricle with enzymes that degrade the CSPG glycosaminoglycans led to reduced cell proliferation and a diminution of self-renewing radial glial cells, as well as increased astrocyte formation at the expense of neuronal differentiation, suggesting a role for CSPG in controlling neural stem/progenitor cell proliferation and neuron-glial cell lineage selection (Sirko et al. 2007). Moreover, spatial temporal regulation of sulfation on chondroitin sulfate polymers modulates the activities of various growth and morphogenetic factors to control neural stem cell proliferation, maintenance and differentiation (Akita et al. 2008;Esko and Selleck 2002). Interaction with the ECM therefore plays a critical role in maintaining the multipotency and migratory capacity of neural stem cells.

An ECM-morphogen interaction is also important in maintaining the stem cell niche. In the germarium of the Drosophila ovary, collagen IV binds to BMP and restricts its movement, thereby promoting short-range BMP signaling to inhibit germline stem cell differentiation (Wang et al. 2008b).

In mammalian tendon, biglycan and fibromodulin are involved in organizing the niche for tendon stem/progenitor cells. In double null mice lacking both biglycan and fibromodulin, the micro-environment of these cells is altered such that BMP signaling increases locally to favor chondrocytic/osteoblastic differentiation and hence ectopic endochondral bone formation, impairing tendon formation in the young adult (Bi et al. 2007). Biglycan may act with decorin to organize the niche for maintaining bone marrow stromal cells (Bi et al. 2005). Mice are osteopenic in the absence of both biglycan and decorin, which may be due to increased TGF $\beta$ and BMP signaling resulting in increased apoptotic elimination of bone marrow stromal cells, thus depleting progenitor cells for 
bone formation (Bi et al. 2005). In addition to interacting with morphogen ligands, these small proteoglycans and other ECM components may regulate collagen fibrillogenesis which determines ECM elasticity, thereby affecting cell fate specification as discussed previously. The bone marrow is also an important site for hematopoietic stem cell niche, the formation of which is dependent on proper endochondral bone formation (Chan et al. 2009) and is suggested to associate with collagen $X$ and perlecan expression in hypertrophic cartilage (Sweeney et al. 2008;Rodgers et al. 2008). Since the ECM molecules are present in various combinations in vivo, it is essential to evaluate the cellular responses to the composition of the ECM to clarify the role of stem cell-substrate interactions during histogenesis. Greater knowledge of this will facilitate the development of bioartificial grafts to improve graft stem/progenitor cell integration and tissue regeneration.

\section{CONCLUDING REMARKS}

The enormous range of possible interactions between a wide variety of secreted molecules and ECM components has produced an extensive repertoire of "net" signals that can be generated in the extracellular space. This pleiotropy permitted the evolution of a great diversity of tissue structures and functions. Animal models help us to explore these relationships and their outcomes and show the dynamic nature of the cell-ECM interaction and tissue morphogenesis under the influence of genetically programmed development. They are irreplaceable tools for us to understand the biology of the ECM in vivo.

However for a number of ECM proteins, loss of function models have not revealed a developmental role, but this does not imply a lack of function. Rather such function may be masked by redundancy or compensation by other ECM molecules or because the functional role is as part of an interacting complex. Gain of function or dominant negative mutations in mice and humans may provide insights into developmental roles fulfilled by combinations of ECM proteins which work together. It is increasingly evident that the ECM plays important roles in modulating availability of morphogens and growth factors. Further discoveries and molecular insight into the role of the ECM in 
controlling the ligand-receptor interactions and signaling activity may be expected. The fruits of the International Knockout Mouse Consortium (Gondo 2008) will certainly enrich and expedite a deeper understanding of the functional roles of the many ECM proteins. Such insight will advance our understanding of molecular pathology of connective tissue diseases and also contribute to regenerative medicine where knowledge of tissue morphogenesis and organogenesis are critical for devising practical therapeutic strategies.

Acknowledgements: The authors are supported by the University Grants Committee of Hong Kong Area of Excellence programme AoE/M-04/04. 


\section{Figure 1. Prototypic cell and ECM interactions in different developmental} scenarios. a., In cartilage, the master transcriptional factor SOX9 specifies chondrocytic fate and activates transcription of cartilage ECM genes such as Col2al, Col11a2, Col9a1, and Agc. Collagens II, IX and XI form fibrils which may interact with $\beta 1$ integrin to regulate chondrocyte proliferation and the architecture of growth plate cartilage. IHH expressed by prehypertrophic and hypertrophic chondrocytes regulates chondrocyte proliferation and differentiation in concert with bone formation. Its diffusion in the ECM is regulated by affinity with HSPGs (e.g. perlecan) and CSPGs (e.g. aggrecan). b., ECM modulates morphogen signaling by interacting directly with BMP and FGF which transduce signals through binding to and activating of their corresponding cell surface receptors. On the other hand, TGF $\beta$ signaling is regulated by tissue elasticity and cytoskeletal tension. TGF $\beta$ is bound to latency-associated protein and latent TGF $\beta$ binding protein, and then released when there is a change in cytoskeletal tension and/or matrix structure. c., A cell niche showing the different categories of ECM and signaling molecules present in the niche that help maintaining the cells in the stem/progenitor state and/or specifying cell fate. d., Epithelial-mesenchymal interaction with reference to a recent model of hair follicle development. Laminin-511 secreted by epidermal cells acts as a paracrine factor to stimulate cilia formation on mesenchymal cells, thereby facilitating PDGF and SHH signaling and consequently Noggin expression. Noggin suppresses BMP signaling in the epidermal cell and promotes SHH expression, forming a positive feedback loop that supports hair follicle development. 


\section{Box 1 Introduction to some basic ECM molecules and structures \\ Collagens}

Collagens are triple helical proteins that confer compressive and tensile strength to animal tissues and serve as anchors for cell adhesion through surface receptors. To date, more than 40 mammalian genes encoding collagen $\alpha$ chains have been described, the products of which combine to form at least 28 distinct homoand heterotrimeric molecules (Myllyharju and Kivirikko 2004;Heino 2007;Gordon and Hahn 2009). The collagen proteins differ considerably in size, structure, tissue distribution and function, but all are characterized by the presence of either continuous or interrupted triple-helical domains made up of repeating Gly-X-Y motifs. Collagen subfamily members form different supramolecular structures such as fibrils (collagens I, II, III, V, XI, XXIV and XXVII), non-fibrillar networks (collagen IV) and lattices (collagens VIII and X). Other subfamilies include fibril-associated collagens (collagens VII, IX, XII, XIV, XVI, XIX, XX, XXI, and XXII) and transmembranous collagens (collagen XIII, XVII, XXIII, and XXV).

\section{Proteoglycans}

Proteoglycans (PGs) consists of a diverse group of core proteins to which sulfated glycosaminoglycans (GAG) side chains are covalently linked. The GAG chains can be classified as keratin sulfate (KS), chondroitin sulfate (CS), dermatan sulfate (DS), and heparan sulfate (HS) (Bulow and Hobert 2006). PGs can be secreted or cell-surface bound and serve diverse function including ECM assembly and mediating cell adhesion and motility. PGs can be generally classified according to the major GAG chains they carried. For example, perlecan is classified as HSPG, but may also carry CS chain especially when expressed in cartilage where the CS may modulate fibroblast growth factor (FGF) signaling (Smith et al. 2007a).

\section{Basement membrane, laminin and collagen IV}

BM is a specialized ECM comprised of laminins and collagen IV networks as central structural components, as well as nidogens and PGs. It is present in many tissues and serves as barrier and structural support. Diversity of BM structure is partly derived from the large numbers of differentially expressed isoforms of laminins. Laminin isoforms are a family of 15 multidomain heterotrimeric glycoproteins, each assembled from a combination of five $\alpha$, three $\beta$ and three $\gamma$ chains (Nguyen and Senior 2006). The nomenclature for the laminins is based on chain numbers, e.g., laminin composed of $\alpha 3 \beta 3 \chi 2$, formerly known as laminin-5, is now called laminin-332 (Aumailley et al. 2005). Collagen IV is a heterotrimeric protomer of three isoforms with the "classic" isoform $\alpha 1_{2} \alpha 2$ (IV) present in $\mathrm{BM}$ of most tissues (Yurchenco et al. 2004; Khoshnoodi et al. 2008). 
Table 1 Examples of ECM components required for proper developmental processes in mouse

\section{Developmental ECM component (mouse model and

processes

Early embryonic Collagen IV (Col4al/Col4a2 dKO; L)

development

Laminin $\alpha 1$ (Lamal KO; L)

Laminin $\beta 1$ (Lamb1 KO; L)

Laminin $\gamma 1($ Lamcl KO; L)

$\begin{array}{ll}\begin{array}{l}\text { Neural crest } \\ \text { migration and }\end{array} & \text { Agrin }(\text { Agrn } \mathrm{KO} \text { and TG; L) } \\ \text { neural } & \text { Fibronectin }(\text { Fn } 1 \mathrm{KO} ; \mathrm{L}) \\ \text { differentiation } & \text { Laminin } \alpha 5(\text { lama } 5 \mathrm{KO} ; \mathrm{L}) \\ & \text { Laminin } \beta 2(\text { lamb2 KO; L) } \\ & \text { Lamcl CKO) }\end{array}$

\section{Notochord Collagen II (Col2al KO; L) \\ development Fibronectin $(F n 1 \mathrm{KO})$}

Chondrogenesis Aggrecan (Acan NM; L)

Collagen II and XI (Col2al KO and Coll1a1 NM,;L; Coll1a2 KO; V)

Link protein (Hapln1 KO; L)

Perlecan (Hspg2 KO; L)

Skin development Collagen III and V (Col3al KO and Col5a1 KO; L), decorin and lumican (Dcn $\mathrm{KO}$ and Lum KO; V)

Laminin $\alpha 5$ (lama5 KO; L)

Nephrogenesis Laminin $\alpha 3, \alpha 5$ and $\beta 2$ (lama3 KO, lama5 $\mathrm{KO}$ and lamb2 $\mathrm{KO}$; L)

Nephronectin (Npnt KO; L)

Stem cell niche Biglycan and fibromodulin (Bgn/Fmod

formation and dKO)

maintenance

Biglycan and decorin (Bgn/Dcn $\mathrm{dKO})$ Collagen X (CollOal KO and TG)
Structural integrity of BM in embryonic vasculature

Formation of Reichert's membrane

Formation of embryonic BM in peri-implantation embryo

Formation of embryonic BM in peri-implantation embryo

Development of the neuromuscular junctions and CNS synapses Proper formation of neural tube

Neural tube closure and neural crest cell migration

Development of the neuromuscular junctions and CNS synapse

Schwann cell proliferation and differentiation, and axon myelination

Remodeling of notochord during intervetebral disc formation Formation of notochord and somites

Structural integrity of cartilage and endochondral bone formation; modulate IHH diffusion

Structural integrity of cartilage and endochondral bone formation

Stabilizing interaction between aggrecan and hyaluronan

Structural integrity of cartilage and endochondral bone formation; modulate FGF signaling

Regulate collagen fibril assembly in the dermis for mechanical strength and resilience of the skin

Hair follicle morphogenesis

Glomerulogenesis

Mediate kidney organogenesis

Regulate the differentiation of tendon stem/progenitor cells for tendon development and formation

Regulate differentiation and survival of osteoprogenitors Contribute to the formation of hematopoietic stem cell niche
(Poschl et al. 2004)

(Miner et al. 2004)

(Miner et al. 2004)

(Smyth et al. 1999)

(Gautam et al. 1996;Ksiazek et al. 2007) (George et al. 1993)

(Miner et al. 1998;Coles et al. 2006)

(Libby et al. 1999; Noakes et al. 1995a)

(Chen and Strickland 2003; Yu et al. 2005)

(Aszodi et al. 1998)

(George et al. 1993)

(Watanabe et al. 1994) (Cortes et al. 2009)

(Li et al. 1995a;Li et al. 1995b;Li et al. 2001)

(Watanabe and Yamada 1999)

(Arikawa-Hirasawa et al. 1999; Costell et al. 1999)

Liu et al. 1997;Andrikopoulos et al.

1995;Danielson et al. 1997; Chakravarti et

al. 1998)

(Li et al. 2003)

(Abrass et al. 2006) (Miner and Li 2000) (Noakes et al. 1995b)

(Linton et al. 2007)

(Bi et al. 2007)

(Bi et al. 2005)

(Sweeney et al. 2008)

Abbreviations: KO, knock-out by gene targeting; CKO, tissue specific conditional KO; dKO, double gene knock-out; NM, natural mutations; L, lethal; TG, transgenic; V, viable.

For an extensive list of gene targeting and natural mutants please refer to (Aszodi et al. 2006). 
Abrass CK, Berfield AK, Ryan MC, Carter WG, Hansen KM (2006) Abnormal development of glomerular endothelial and mesangial cells in mice with targeted disruption of the lama3 gene. Kidney Int 70:1062-1071

Akimov SS, Belkin AM (2001) Cell-surface transglutaminase promotes fibronectin assembly via interaction with the gelatin-binding domain of fibronectin: a role in TGFbeta-dependent matrix deposition. J Cell Sci 114:2989-3000

Akita K, von Holst A, Furukawa Y, Mikami T, Sugahara K, Faissner A (2008) Expression of multiple chondroitin/dermatan sulfotransferases in the neurogenic regions of the embryonic and adult central nervous system implies that complex chondroitin sulfates have a role in neural stem cell maintenance. Stem Cells 26:

Akiyama H, Chaboissier MC, Martin JF, Schedl A, de CB (2002) The transcription factor Sox9 has essential roles in successive steps of the chondrocyte differentiation pathway and is required for expression of Sox 5 and Sox6. Genes Dev 16:2813-2828

Akiyama T, Kamimura K, Firkus C, Takeo S, Shimmi O, Nakato H (2008) Dally regulates Dpp morphogen gradient formation by stabilizing Dpp on the cell surface. Dev Biol 313:408-419

Ambrosio AL, Taelman VF, Lee HX, Metzinger CA, Coffinier C, De Robertis EM (2008) Crossveinless-2 Is a BMP feedback inhibitor that binds Chordin/BMP to regulate Xenopus embryonic patterning. Dev Cell 15:248-260

Ameye L, Aria D, Jepsen K, Oldberg A, Xu T, Young MF (2002) Abnormal collagen fibrils in tendons of biglycan/fibromodulindeficient mice lead to gait impairment, ectopic ossification, and osteoarthritis. FASEB J 16:673-680

Andressen C, Arnhold S, Puschmann M, Bloch W, Hescheler J, Fassler R, Addicks K (1998) Beta1 integrin deficiency impairs migration and differentiation of mouse embryonic stem cell derived neurons. Neurosci Lett 251:

Andrikopoulos K, Liu X, Keene DR, Jaenisch R, Ramirez F (1995) Targeted mutation in the col5a2 gene reveals a regulatory role for type $\mathrm{V}$ collagen during matrix assembly. Nat Genet 9:31-36 
Aouacheria A, Geourjon C, Aghajari N, Navratil V, Deleage G, Lethias C, Exposito JY (2006) Insights into early extracellular matrix evolution: spongin short chain collagen-related proteins are homologous to basement membrane type IV collagens and form a novel family widely distributed in invertebrates. Mol Biol Evol 23:2288-2302

Arikawa-Hirasawa E, Watanabe H, Takami H, Hassell JR, Yamada Y (1999) Perlecan is essential for cartilage and cephalic development. Nat Genet 23:354-358

Arteaga-Solis E, Gayraud B, Lee SY, Shum L, Sakai L, Ramirez F (2001) Regulation of limb patterning by extracellular microfibrils. J Cell Biol 154:275-281

Aszodi A, Chan D, Hunziker E, Bateman JF, Fassler R (1998) Collagen II is essential for the removal of the notochord and the formation of intervertebral discs. J Cell Biol 143:1399-1412

Aszodi A, Hunziker EB, Brakebusch C, Fassler R (2003) Beta1 integrins regulate chondrocyte rotation, G1 progression, and cytokinesis. Genes Dev 17:2465-2479

Aszodi A, Legate KR, Nakchbandi I, Fassler R (2006) What mouse mutants teach us about extracellular matrix function. Annu Rev Cell Dev Biol 22:591-621

Aumailley M, Bruckner-Tuderman L, Carter WG, Deutzmann R, Edgar D, Ekblom P, Engel J, Engvall E, Hohenester E, Jones JC, Kleinman HK, Marinkovich MP, Martin GR, Mayer U, Meneguzzi G, Miner JH, Miyazaki K, Patarroyo M, Paulsson M, Quaranta V, Sanes JR, Sasaki T, Sekiguchi K, Sorokin LM, Talts JF, Tryggvason K, Uitto J, Virtanen I, von der MK, Wewer UM, Yamada Y, Yurchenco PD (2005) A simplified laminin nomenclature. Matrix Biol 24:326-332

Banos CC, Thomas AH, Kuo CK (2008) Collagen fibrillogenesis in tendon development: current models and regulation of fibril assembly. Birth Defects Res C Embryo Today 84:228-244

Barrionuevo F, Taketo MM, Scherer G, Kispert A (2006) Sox9 is required for notochord maintenance in mice. Dev Biol 295:128-140

Bell DM, Leung KK, Wheatley SC, Ng LJ, Zhou S, Ling KW, Sham MH, Koopman P, Tam PP, Cheah KS (1997) SOX9 directly regulates the type-II collagen gene. Nat Genet 16:174-178 
Bi Y, Ehirchiou D, Kilts TM, Inkson CA, Embree MC, Sonoyama W, Li L, Leet AI, Seo BM, Zhang L, Shi S, Young MF (2007) Identification of tendon stem/progenitor cells and the role of the extracellular matrix in their niche. Nat Med 13:1219-1227

Bi Y, Stuelten CH, Kilts T, Wadhwa S, Iozzo RV, Robey PG, Chen XD, Young MF (2005) Extracellular matrix proteoglycans control the fate of bone marrow stromal cells. J Biol Chem 280:30481-30489

Bier E (2008) Intriguing extracellular regulation of BMP signaling. Dev Cell 15:176-177

Bridgewater LC, Walker MD, Miller GC, Ellison TA, Holsinger LD, Potter JL, Jackson TL, Chen RK, Winkel VL, Zhang Z, McKinney S, de CB (2003) Adjacent DNA sequences modulate Sox9 transcriptional activation at paired Sox sites in three chondrocyte-specific enhancer elements. Nucleic Acids Res 31:1541-1553

Bronner-Fraser M (1988) Distribution and function of tenascin during cranial neural crest development in the chick. J Neurosci Res 21 :

Bulow HE, Hobert O (2006) The molecular diversity of glycosaminoglycans shapes animal development. Annu Rev Cell Dev Biol 22:375-407

Cardoso WV, Lu J (2006) Regulation of early lung morphogenesis: questions, facts and controversies. Development 133:1611-1624

Chakravarti S, Magnuson T, Lass JH, Jepsen KJ, LaMantia C, Carroll H (1998) Lumican regulates collagen fibril assembly: skin fragility and corneal opacity in the absence of lumican. J Cell Biol 141:1277-1286

Chakravarti S, Zhang G, Chervoneva I, Roberts L, Birk DE (2006) Collagen fibril assembly during postnatal development and dysfunctional regulation in the lumican-deficient murine cornea. Dev Dyn 235:2493-2506

Chan CK, Chen CC, Luppen CA, Kim JB, DeBoer AT, Wei K, Helms JA, Kuo CJ, Kraft DL, Weissman IL (2009) Endochondral ossification is required for haematopoietic stem-cell niche formation. Nature 457:490-494

Chang W, Lin Z, Kulessa H, Hebert J, Hogan BL, Wu DK (2008b) Bmp4 is essential for the formation of the vestibular apparatus that detects angular head movements. PLoS Genet 4:e1000050 
Chang W, Lin Z, Kulessa H, Hebert J, Hogan BL, Wu DK (2008a) Bmp4 is essential for the formation of the vestibular apparatus that detects angular head movements. PLoS Genet 4:e1000050

Cheah KSE, Wong SYY, Zhang JCL, Leung AWL, Chan D, Tam PPL (2005) Procollagen IIA regulates BMP/TGFb signaling in patterning the heart and its major vessels. Mechanisms of Development 122 (Supp1):S25

Chen ZL, Strickland S (2003) Laminin gammal is critical for Schwann cell differentiation, axon myelination, and regeneration in the peripheral nerve. J Cell Biol 163:889-899

Coles EG, Gammill LS, Miner JH, Bronner-Fraser M (2006) Abnormalities in neural crest cell migration in laminin alpha5 mutant mice. Dev Biol 289:

Cortes M, Baria AT, Schwartz NB (2009) Sulfation of chondroitin sulfate proteoglycans is necessary for proper Indian hedgehog signaling in the developing growth plate. Development 136:1697-1706

Costa-Silva B, da Costa MC, Melo FR, Neves CM, Alvarez-Silva M, Calloni GW, Trentin AG (2009) Fibronectin promotes differentiation of neural crest progenitors endowed with smooth muscle cell potential. Exp Cell Res 315:

Costantini F, Shakya R (2006) GDNF/Ret signaling and the development of the kidney. Bioessays 28:117-127

Costell M, Gustafsson E, Aszodi A, Morgelin M, Bloch W, Hunziker E, Addicks K, Timpl R, Fassler R (1999) Perlecan maintains the integrity of cartilage and some basement membranes. J Cell Biol 147:1109-1122

Danielson KG, Baribault H, Holmes DF, Graham H, Kadler KE, Iozzo RV (1997) Targeted disruption of decorin leads to abnormal collagen fibril morphology and skin fragility. J Cell Biol 136:729-743

De ML, Spencer-Dene B, Revest JM, Hajihosseini M, Rosewell I, Dickson C (2000) An important role for the IIIb isoform of fibroblast growth factor receptor 2 (FGFR2) in mesenchymal-epithelial signalling during mouse organogenesis. Development $127: 483-492$

Delannet M, Martin F, Bossy B, Cheresh DA, Reichardt LF, Duband JL (1994) Specific roles of the alpha V beta 1, alpha V beta 3 and alpha $\mathrm{V}$ beta 5 integrins in avian neural crest cell adhesion and migration on vitronectin. Development 120: 
Drago J, Nurcombe V, Bartlett PF (1991) Laminin through its long arm E8 fragment promotes the proliferation and differentiation of murine neuroepithelial cells in vitro. Exp Cell Res 192:

Duband JL, Rocher S, Yamada KM, Thiery JP (1986) Interactions of migrating neural crest cells with fibronectin. Prog Clin Biol Res 226:

Duband JL, Thiery JP (1987) Distribution of laminin and collagens during avian neural crest development. Development 101:

Engler AJ, Carag-Krieger C, Johnson CP, Raab M, Tang HY, Speicher DW, Sanger JW, Sanger JM, Discher DE (2008) Embryonic cardiomyocytes beat best on a matrix with heart-like elasticity: scar-like rigidity inhibits beating. J Cell Sci 121:3794-3802

Engler AJ, Sen S, Sweeney HL, Discher DE (2006) Matrix elasticity directs stem cell lineage specification. Cell 126:677-689

Entesarian M, Matsson H, Klar J, Bergendal B, Olson L, Arakaki R, Hayashi Y, Ohuchi H, Falahat B, Bolstad AI, Jonsson R, Wahren-Herlenius M, Dahl N (2005) Mutations in the gene encoding fibroblast growth factor 10 are associated with aplasia of lacrimal and salivary glands. Nat Genet 37:125-127

Esko JD, Selleck SB (2002) Order out of chaos: assembly of ligand binding sites in heparan sulfate. Annu Rev Biochem 71:

Flanagan LA, Rebaza LM, Derzic S, Schwartz PH, Monuki ES (2006) Regulation of human neural precursor cells by laminin and integrins. J Neurosci Res 83:

Fontana L, Chen Y, Prijatelj P, Sakai T, Fassler R, Sakai LY, Rifkin DB (2005) Fibronectin is required for integrin alphavbeta6mediated activation of latent TGF-beta complexes containing LTBP-1. FASEB J 19:1798-1808

Fox MA, Sanes JR, Borza DB, Eswarakumar VP, Fassler R, Hudson BG, John SW, Ninomiya Y, Pedchenko V, Pfaff SL, Rheault MN, Sado Y, Segal Y, Werle MJ, Umemori H (2007) Distinct target-derived signals organize formation, maturation, and maintenance of motor nerve terminals. Cell 129:179-193

Fujiwara H, Hayashi Y, Sanzen N, Kobayashi R, Weber CN, Emoto T, Futaki S, Niwa H, Murray P, Edgar D, Sekiguchi K (2007) Regulation of mesodermal differentiation of mouse embryonic stem cells by basement membranes. J Biol Chem 282:29701-29711 
Gao J, DeRouen MC, Chen CH, Nguyen M, Nguyen NT, Ido H, Harada K, Sekiguchi K, Morgan BA, Miner JH, Oro AE, Marinkovich MP (2008) Laminin-511 is an epithelial message promoting dermal papilla development and function during early hair morphogenesis. Genes Dev 22:2111-2124

Gautam M, Noakes PG, Moscoso L, Rupp F, Scheller RH, Merlie JP, Sanes JR (1996) Defective neuromuscular synaptogenesis in agrin-deficient mutant mice. Cell 85:525-535

George EL, Georges-Labouesse EN, Patel-King RS, Rayburn H, Hynes RO (1993) Defects in mesoderm, neural tube and vascular development in mouse embryos lacking fibronectin. Development 119:1079-1091

Goh KL, Yang JT, Hynes RO (1997) Mesodermal defects and cranial neural crest apoptosis in alpha5 integrin-null embryos. Development 124:4309-4319

Gondo Y (2008) Trends in large-scale mouse mutagenesis: from genetics to functional genomics. Nat Rev Genet 9:803-810

Gordon MK, Hahn RA (2009) Collagens. Cell Tissue Res

Gotz W, Osmers R, Herken R (1995) Localisation of extracellular matrix components in the embryonic human notochord and axial mesenchyme. J Anat 186 ( Pt 1):111-121

Han Y, Lefebvre V (2008b) L-Sox5 and Sox6 drive expression of the aggrecan gene in cartilage by securing binding of Sox9 to a farupstream enhancer. Mol Cell Biol 28:4999-5013

Han Y, Lefebvre V (2008a) L-Sox5 and Sox6 drive expression of the aggrecan gene in cartilage by securing binding of Sox9 to a farupstream enhancer. Mol Cell Biol 28:4999-5013

Harada M, Murakami H, Okawa A, Okimoto N, Hiraoka S, Nakahara T, Akasaka R, Shiraishi Y, Futatsugi N, Mizutani-Koseki Y, Kuroiwa A, Shirouzu M, Yokoyama S, Taiji M, Iseki S, Ornitz DM, Koseki H (2009) FGF9 monomer-dimer equilibrium regulates extracellular matrix affinity and tissue diffusion. Nat Genet 41:289-298

Hashizume A, Hieda Y (2006) Hedgehog peptide promotes cell polarization and lumen formation in developing mouse submandibular gland. Biochem Biophys Res Commun 339:996-1000 
Hayes AJ, Benjamin M, Ralphs JR (2001) Extracellular matrix in development of the intervertebral disc. Matrix Biol 20:107-121

Heino J (2007) The collagen family members as cell adhesion proteins. Bioessays 29:1001-1010

Henriquez JP, Webb A, Bence M, Bildsoe H, Sahores M, Hughes SM, Salinas PC (2008) Wnt signaling promotes AChR aggregation at the neuromuscular synapse in collaboration with agrin. Proc Natl Acad Sci U S A 105:18812-18817

Hoffman MP, Kidder BL, Steinberg ZL, Lakhani S, Ho S, Kleinman HK, Larsen M (2002) Gene expression profiles of mouse submandibular gland development: FGFR1 regulates branching morphogenesis in vitro through BMP- and FGF-dependent mechanisms. Development 129:5767-5778

Holster T, Pakkanen O, Soininen R, Sormunen R, Nokelainen M, Kivirikko KI, Myllyharju J (2007) Loss of assembly of the main basement membrane collagen, type IV, but not fibril-forming collagens and embryonic death in collagen prolyl 4-hydroxylase I null mice. J Biol Chem 282:2512-2519

Hu H, Hilton MJ, Tu X, Yu K, Ornitz DM, Long F (2005) Sequential roles of Hedgehog and Wnt signaling in osteoblast development. Development 132:49-60

Ikeya M, Nosaka T, Fukushima K, Kawada M, Furuta Y, Kitamura T, Sasai Y (2008) Twisted gastrulation mutation suppresses skeletal defect phenotypes in Crossveinless 2 mutant mice. Mech Dev 125:832-842

Jaskoll T, Abichaker G, Witcher D, Sala FG, Bellusci S, Hajihosseini MK, Melnick M (2005) FGF10/FGFR2b signaling plays essential roles during in vivo embryonic submandibular salivary gland morphogenesis. BMC Dev Biol 5:11

Jaskoll T, Leo T, Witcher D, Ormestad M, Astorga J, Bringas P, Jr., Carlsson P, Melnick M (2004a) Sonic hedgehog signaling plays an essential role during embryonic salivary gland epithelial branching morphogenesis. Dev Dyn 229:722-732

Jaskoll T, Melnick M (1999) Submandibular gland morphogenesis: stage-specific expression of TGF-alpha/EGF, IGF, TGF-beta, TNF, and IL-6 signal transduction in normal embryonic mice and the phenotypic effects of TGF-beta2, TGF-beta3, and EGF-r null mutations. Anat Rec 256:252-268 
Jaskoll T, Witcher D, Toreno L, Bringas P, Moon AM, Melnick M (2004b) FGF8 dose-dependent regulation of embryonic submandibular salivary gland morphogenesis. Dev Biol 268:457-469

Jaskoll T, Zhou YM, Chai Y, Makarenkova HP, Collinson JM, West JD, Hajihosseini MK, Lee J, Melnick M (2002) Embryonic submandibular gland morphogenesis: stage-specific protein localization of FGFs, BMPs, Pax6 and Pax9 in normal mice and abnormal SMG phenotypes in FgfR2-IIIc(+/Delta), BMP7(-/-) and Pax6(-/-) mice. Cells Tissues Organs 170:83-98

Jia J, Maccarana M, Zhang X, Bespalov M, Lindahl U, Li JP (2009) Lack of L-iduronic acid in heparan sulfate affects interaction with growth factors and cell signaling. J Biol Chem 284:15942-15950

Kadler KE, Hill A, Canty-Laird EG (2008) Collagen fibrillogenesis: fibronectin, integrins, and minor collagens as organizers and nucleators. Curr Opin Cell Biol 20:495-501

Kalyani A, Hobson K, Rao MS (1997) Neuroepithelial stem cells from the embryonic spinal cord: isolation, characterization, and clonal analysis. Dev Biol 186:

Kearns SM, Laywell ED, Kukekov VK, Steindler DA (2003) Extracellular matrix effects on neurosphere cell motility. Exp Neurol 182:

Khetarpal U, Robertson NG, Yoo TJ, Morton CC (1994) Expression and localization of COL2A1 mRNA and type II collagen in human fetal cochlea. Hear Res 79:59-73

Khoshnoodi J, Pedchenko V, Hudson BG (2008) Mammalian collagen IV. Microsc Res Tech 71:357-370

Kronenberg HM (2003) Developmental regulation of the growth plate. Nature 423:332-336

Krotoski DM, Bronner-Fraser M (1986) Mapping of neural crest pathways in Xenopus laevis. Prog Clin Biol Res 217B:

Ksiazek I, Burkhardt C, Lin S, Seddik R, Maj M, Bezakova G, Jucker M, Arber S, Caroni P, Sanes JR, Bettler B, Ruegg MA (2007) Synapse loss in cortex of agrin-deficient mice after genetic rescue of perinatal death. J Neurosci 27:7183-7195 
Kukekov VG, Laywell ED, Suslov O, Davies K, Scheffler B, Thomas LB, O'Brien TF, Kusakabe M, Steindler DA (1999) Multipotent stem/progenitor cells with similar properties arise from two neurogenic regions of adult human brain. Exp Neurol 156:

Lallier T, Leblanc G, Artinger KB, Bronner-Fraser M (1992) Cranial and trunk neural crest cells use different mechanisms for attachment to extracellular matrices. Development 116:

Landolt RM, Vaughan L, Winterhalter KH, Zimmermann DR (1995) Versican is selectively expressed in embryonic tissues that act as barriers to neural crest cell migration and axon outgrowth. Development 121:

Larrain J, Bachiller D, Lu B, Agius E, Piccolo S, De Robertis EM (2000) BMP-binding modules in chordin: a model for signalling regulation in the extracellular space. Development 127:821-830

Laywell ED, Kukekov VG, Steindler DA (1999) Multipotent neurospheres can be derived from forebrain subependymal zone and spinal cord of adult mice after protracted postmortem intervals. Exp Neurol 156:

Laywell ED, Rakic P, Kukekov VG, Holland EC, Steindler DA (2000) Identification of a multipotent astrocytic stem cell in the immature and adult mouse brain. Proc Natl Acad Sci U S A 97:

Le Douarin N (2001) [The neural crest and evolution of vertebrates]. Bull Mem Acad R Med Belg 156:

Lefebvre V, Huang W, Harley VR, Goodfellow PN, de CB (1997) SOX9 is a potent activator of the chondrocyte-specific enhancer of the pro alpha1(II) collagen gene. Mol Cell Biol 17:2336-2346

Leone DP, Relvas JB, Campos LS, Hemmi S, Brakebusch C, Fassler R, Ffrench-Constant C, Suter U (2005) Regulation of neural progenitor proliferation and survival by beta1 integrins. J Cell Sci 118:

Li H, Corrales CE, Wang Z, Zhao Y, Wang Y, Liu H, Heller S (2005) BMP4 signaling is involved in the generation of inner ear sensory epithelia. BMC Dev Biol 5:16

Li J, Tzu J, Chen Y, Zhang YP, Nguyen NT, Gao J, Bradley M, Keene DR, Oro AE, Miner JH, Marinkovich MP (2003) Laminin-10 is crucial for hair morphogenesis. EMBO J 22:2400-2410 
Li SW, Prockop DJ, Helminen H, Fassler R, Lapvetelainen T, Kiraly K, Peltarri A, Arokoski J, Lui H, Arita M, . (1995a) Transgenic mice with targeted inactivation of the Col2 alpha 1 gene for collagen II develop a skeleton with membranous and periosteal bone but no endochondral bone. Genes Dev 9:2821-2830

Li SW, Takanosu M, Arita M, Bao Y, Ren ZX, Maier A, Prockop DJ, Mayne R (2001) Targeted disruption of Col11a2 produces a mild cartilage phenotype in transgenic mice: comparison with the human disorder otospondylomegaepiphyseal dysplasia (OSMED). Dev Dyn 222:141-152

Li Y, Lacerda DA, Warman ML, Beier DR, Yoshioka H, Ninomiya Y, Oxford JT, Morris NP, Andrikopoulos K, Ramirez F, . (1995b) A fibrillar collagen gene, Col11a1, is essential for skeletal morphogenesis. Cell 80:423-430

Libby RT, Lavallee CR, Balkema GW, Brunken WJ, Hunter DD (1999) Disruption of laminin beta2 chain production causes alterations in morphology and function in the CNS. J Neurosci 19:9399-9411

Lincoln J, Florer JB, Deutsch GH, Wenstrup RJ, Yutzey KE (2006) ColVa1 and ColXIa1 are required for myocardial morphogenesis and heart valve development. Dev Dyn 235:3295-3305

Linton JM, Martin GR, Reichardt LF (2007) The ECM protein nephronectin promotes kidney development via integrin alpha8beta1mediated stimulation of Gdnf expression. Development 134:2501-2509

Liu X, Wu H, Byrne M, Krane S, Jaenisch R (1997) Type III collagen is crucial for collagen I fibrillogenesis and for normal cardiovascular development. Proc Natl Acad Sci U S A 94:1852-1856

Lui VC, Ng LJ, Nicholls J, Tam PP, Cheah KS (1995) Tissue-specific and differential expression of alternatively spliced alpha 1(II) collagen mRNAs in early human embryos. Dev Dyn 203:198-211

Luo G, Ducy P, McKee MD, Pinero GJ, Loyer E, Behringer RR, Karsenty G (1997) Spontaneous calcification of arteries and cartilage in mice lacking matrix GLA protein. Nature 386:78-81

Majumdar A, Vainio S, Kispert A, McMahon J, McMahon AP (2003) Wnt11 and Ret/Gdnf pathways cooperate in regulating ureteric branching during metanephric kidney development. Development 130:3175-3185 
Mak AC, Szeto IY, Fritzsch B, Cheah KS (2009) Differential and overlapping expression pattern of SOX2 and SOX9 in inner ear development. Gene Expr Patterns

Matthews HK, Marchant L, Carmona-Fontaine C, Kuriyama S, Larrain J, Holt MR, Parsons M, Mayor R (2008) Directional migration of neural crest cells in vivo is regulated by Syndecan-4/Rac1 and non-canonical Wnt signaling/RhoA. Development 135:

Melrose J, Roughley P, Knox S, Smith S, Lord M, Whitelock J (2006) The structure, location, and function of perlecan, a prominent pericellular proteoglycan of fetal, postnatal, and mature hyaline cartilages. J Biol Chem 281:36905-36914

Metzger RJ, Klein OD, Martin GR, Krasnow MA (2008) The branching programme of mouse lung development. Nature 453:745-750

Michos O, Goncalves A, Lopez-Rios J, Tiecke E, Naillat F, Beier K, Galli A, Vainio S, Zeller R (2007) Reduction of BMP4 activity by gremlin 1 enables ureteric bud outgrowth and GDNF/WNT11 feedback signalling during kidney branching morphogenesis.

Development 134:2397-2405

Michos O, Panman L, Vintersten K, Beier K, Zeller R, Zuniga A (2004) Gremlin-mediated BMP antagonism induces the epithelialmesenchymal feedback signaling controlling metanephric kidney and limb organogenesis. Development 131:3401-3410

Min H, Danilenko DM, Scully SA, Bolon B, Ring BD, Tarpley JE, DeRose M, Simonet WS (1998) Fgf-10 is required for both limb and lung development and exhibits striking functional similarity to Drosophila branchless. Genes Dev 12:3156-3161

Miner JH, Cunningham J, Sanes JR (1998) Roles for laminin in embryogenesis: exencephaly, syndactyly, and placentopathy in mice lacking the laminin alpha5 chain. J Cell Biol 143:1713-1723

Miner JH, Li C (2000) Defective glomerulogenesis in the absence of laminin alpha5 demonstrates a developmental role for the kidney glomerular basement membrane. Dev Biol 217:278-289

Miner JH, Li C, Mudd JL, Go G, Sutherland AE (2004) Compositional and structural requirements for laminin and basement membranes during mouse embryo implantation and gastrulation. Development 131:2247-2256

Monne M, Han L, Schwend T, Burendahl S, Jovine L (2008) Crystal structure of the ZP-N domain of ZP3 reveals the core fold of animal egg coats. Nature 456:653-657 
Murakami H, Okawa A, Yoshida H, Nishikawa S, Moriya H, Koseki H (2002) Elbow knee synostosis (Eks): a new mutation on mouse Chromosome 14. Mamm Genome 13:341-344

Murase S, Horwitz AF (2002) Deleted in colorectal carcinoma and differentially expressed integrins mediate the directional migration of neural precursors in the rostral migratory stream. J Neurosci 22:

Myllyharju J, Kivirikko KI (2004) Collagens, modifying enzymes and their mutations in humans, flies and worms. Trends Genet 20:33-43

Nagai N, Hosokawa M, Itohara S, Adachi E, Matsushita T, Hosokawa N, Nagata K (2000) Embryonic lethality of molecular chaperone hsp47 knockout mice is associated with defects in collagen biosynthesis. J Cell Biol 150:1499-1506

Nakrieko KA, Welch I, Dupuis H, Bryce D, Pajak A, St AR, Dedhar S, D'Souza SJ, Dagnino L (2008) Impaired hair follicle morphogenesis and polarized keratinocyte movement upon conditional inactivation of integrin-linked kinase in the epidermis. Mol Biol Cell 19:1462-1473

Newgreen D, Thiery JP (1980) Fibronectin in early avian embryos: synthesis and distribution along the migration pathways of neural crest cells. Cell Tissue Res 211:

Newgreen DF (1989) Physical influences on neural crest cell migration in avian embryos: contact guidance and spatial restriction. Dev Biol 131:

Nguyen NM, Kelley DG, Schlueter JA, Meyer MJ, Senior RM, Miner JH (2005) Epithelial laminin alpha5 is necessary for distal epithelial cell maturation, VEGF production, and alveolization in the developing murine lung. Dev Biol 282:111-125

Nguyen NM, Miner JH, Pierce RA, Senior RM (2002) Laminin alpha 5 is required for lobar septation and visceral pleural basement membrane formation in the developing mouse lung. Dev Biol 246:231-244

Nguyen NM, Senior RM (2006) Laminin isoforms and lung development: all isoforms are not equal. Dev Biol 294:271-279

Nishimune H, Valdez G, Jarad G, Moulson CL, Muller U, Miner JH, Sanes JR (2008) Laminins promote postsynaptic maturation by an autocrine mechanism at the neuromuscular junction. J Cell Biol 182:1201-1215 
Noakes PG, Gautam M, Mudd J, Sanes JR, Merlie JP (1995a) Aberrant differentiation of neuromuscular junctions in mice lacking slaminin/laminin beta 2. Nature 374:258-262

Noakes PG, Miner JH, Gautam M, Cunningham JM, Sanes JR, Merlie JP (1995b) The renal glomerulus of mice lacking slaminin/laminin beta 2: nephrosis despite molecular compensation by laminin beta 1. Nat Genet 10:400-406

Novak U, Kaye AH (2000) Extracellular matrix and the brain: components and function. J Clin Neurosci 7:

Ornitz DM (2000) FGFs, heparan sulfate and FGFRs: complex interactions essential for development. Bioessays 22:108-112

Patel VN, Knox SM, Likar KM, Lathrop CA, Hossain R, Eftekhari S, Whitelock JM, Elkin M, Vlodavsky I, Hoffman MP (2007) Heparanase cleavage of perlecan heparan sulfate modulates FGF10 activity during ex vivo submandibular gland branching morphogenesis. Development 134:4177-4186

Peacock JD, Lu Y, Koch M, Kadler KE, Lincoln J (2008) Temporal and spatial expression of collagens during murine atrioventricular heart valve development and maintenance. Dev Dyn 237:3051-3058

Perris R, Krotoski D, Bronner-Fraser M (1991) Collagens in avian neural crest development: distribution in vivo and migrationpromoting ability in vitro. Development 113:

Perris R, Kuo HJ, Glanville RW, Leibold S, Bronner-Fraser M (1993a) Neural crest cell interaction with type VI collagen is mediated by multiple cooperative binding sites within triple-helix and globular domains. Exp Cell Res 209:

Perris R, Perissinotto D, Pettway Z, Bronner-Fraser M, Morgelin M, Kimata K (1996) Inhibitory effects of PG-H/aggrecan and PG$\mathrm{M} /$ versican on avian neural crest cell migration. FASEB J 10:

Perris R, Syfrig J, Paulsson M, Bronner-Fraser M (1993b) Molecular mechanisms of neural crest cell attachment and migration on types I and IV collagen. J Cell Sci 106 ( Pt 4):

Poschl E, Schlotzer-Schrehardt U, Brachvogel B, Saito K, Ninomiya Y, Mayer U (2004) Collagen IV is essential for basement membrane stability but dispensable for initiation of its assembly during early development. Development 131:1619-1628 
Pujades C, Kamaid A, Alsina B, Giraldez F (2006) BMP-signaling regulates the generation of hair-cells. Dev Biol 292:55-67

Ramirez F, Sakai LY (2009) Biogenesis and function of fibrillin assemblies. Cell Tissue Res

Rautavuoma K, Takaluoma K, Sormunen R, Myllyharju J, Kivirikko KI, Soininen R (2004) Premature aggregation of type IV collagen and early lethality in lysyl hydroxylase 3 null mice. Proc Natl Acad Sci U S A 101:14120-14125

Rebustini IT, Patel VN, Stewart JS, Layvey A, Georges-Labouesse E, Miner JH, Hoffman MP (2007) Laminin alpha5 is necessary for submandibular gland epithelial morphogenesis and influences FGFR expression through beta1 integrin signaling. Dev Biol 308:15-29

Ring C, Hassell J, Halfter W (1996) Expression pattern of collagen IX and potential role in the segmentation of the peripheral nervous system. Dev Biol 180:

Rodda SJ, McMahon AP (2006) Distinct roles for Hedgehog and canonical Wnt signaling in specification, differentiation and maintenance of osteoblast progenitors. Development 133:3231-3244

Rodgers KD, San Antonio JD, Jacenko O (2008) Heparan sulfate proteoglycans: a GAGgle of skeletal-hematopoietic regulators. Dev Dyn 237:2622-2642

Rossi M, Morita H, Sormunen R, Airenne S, Kreivi M, Wang L, Fukai N, Olsen BR, Tryggvason K, Soininen R (2003) Heparan sulfate chains of perlecan are indispensable in the lens capsule but not in the kidney. EMBO J 22:236-245

Ruotsalainen H, Sipila L, Vapola M, Sormunen R, Salo AM, Uitto L, Mercer DK, Robins SP, Risteli M, Aszodi A, Fassler R, Myllyla R (2006) Glycosylation catalyzed by lysyl hydroxylase 3 is essential for basement membranes. J Cell Sci 119:625-635

Sakai T, Larsen M, Yamada KM (2003) Fibronectin requirement in branching morphogenesis. Nature 423:876-881

Schuger L, O'Shea KS, Nelson BB, Varani J (1990a) Organotypic arrangement of mouse embryonic lung cells on a basement membrane extract: involvement of laminin. Development 110:1091-1099

Schuger L, O'Shea S, Rheinheimer J, Varani J (1990b) Laminin in lung development: effects of anti-laminin antibody in murine lung morphogenesis. Dev Biol 137:26-32 
Schuger L, Skubitz AP, O'Shea KS, Chang JF, Varani J (1991) Identification of laminin domains involved in branching morphogenesis: effects of anti-laminin monoclonal antibodies on mouse embryonic lung development. Dev Biol 146:531-541

Sekine K, Ohuchi H, Fujiwara M, Yamasaki M, Yoshizawa T, Sato T, Yagishita N, Matsui D, Koga Y, Itoh N, Kato S (1999) Fgf10 is essential for limb and lung formation. Nat Genet 21:138-141

Sengle G, Charbonneau NL, Ono RN, Sasaki T, Alvarez J, Keene DR, Bachinger HP, Sakai LY (2008) Targeting of bone morphogenetic protein growth factor complexes to fibrillin. J Biol Chem 283:13874-13888

Sirko S, von Holst A, Wizenmann A, Gotz M, Faissner A (2007) Chondroitin sulfate glycosaminoglycans control proliferation, radial glia cell differentiation and neurogenesis in neural stem/progenitor cells. Development 134:

Smirnov SP, Barzaghi P, McKee KK, Ruegg MA, Yurchenco PD (2005) Conjugation of LG domains of agrins and perlecan to polymerizing laminin-2 promotes acetylcholine receptor clustering. J Biol Chem 280:41449-41457

Smith SM, West LA, Govindraj P, Zhang X, Ornitz DM, Hassell JR (2007a) Heparan and chondroitin sulfate on growth plate perlecan mediate binding and delivery of FGF-2 to FGF receptors. Matrix Biol 26:175-184

Smith SM, West LA, Hassell JR (2007b) The core protein of growth plate perlecan binds FGF-18 and alters its mitogenic effect on chondrocytes. Arch Biochem Biophys 468:244-251

Smits P, Lefebvre V (2003) Sox5 and Sox6 are required for notochord extracellular matrix sheath formation, notochord cell survival and development of the nucleus pulposus of intervertebral discs. Development 130:1135-1148

Smits P, Li P, Mandel J, Zhang Z, Deng JM, Behringer RR, de CB, Lefebvre V (2001) The transcription factors L-Sox5 and Sox6 are essential for cartilage formation. Dev Cell 1:277-290

Smyth N, Vatansever HS, Murray P, Meyer M, Frie C, Paulsson M, Edgar D (1999) Absence of basement membranes after targeting the LAMC1 gene results in embryonic lethality due to failure of endoderm differentiation. J Cell Biol 144:151-160

So CL, Kaluarachchi K, Tam PP, Cheah KS (2001) Impact of mutations of cartilage matrix genes on matrix structure, gene activity and chondrogenesis. Osteoarthritis Cartilage 9 Suppl A:S160-S173 
Steinberg Z, Myers C, Heim VM, Lathrop CA, Rebustini IT, Stewart JS, Larsen M, Hoffman MP (2005) FGFR2b signaling regulates ex vivo submandibular gland epithelial cell proliferation and branching morphogenesis. Development 132:1223-1234

Stemple DL (2005) Structure and function of the notochord: an essential organ for chordate development. Development 132:25032512

Strachan LR, Condic ML (2003) Neural crest motility and integrin regulation are distinct in cranial and trunk populations. Dev Biol 259:

Sugahara K, Mikami T (2007) Chondroitin/dermatan sulfate in the central nervous system. Curr Opin Struct Biol 17:

Sweeney E, Campbell M, Watkins K, Hunter CA, Jacenko O (2008) Altered endochondral ossification in collagen X mouse models leads to impaired immune responses. Dev Dyn 237:2693-2704

Tan SS, Crossin KL, Hoffman S, Edelman GM (1987) Asymmetric expression in somites of cytotactin and its proteoglycan ligand is correlated with neural crest cell distribution. Proc Natl Acad Sci U S A 84:

Testaz S, Duband JL (2001) Central role of the alpha4beta1 integrin in the coordination of avian truncal neural crest cell adhesion, migration, and survival. Dev Dyn 222:

Tholozan FM, Gribbon C, Li Z, Goldberg MW, Prescott AR, McKie N, Quinlan RA (2007) FGF-2 release from the lens capsule by MMP-2 maintains lens epithelial cell viability. Mol Biol Cell 18:4222-4231

Tiainen P, Pasanen A, Sormunen R, Myllyharju J (2008) Characterization of recombinant human prolyl 3-hydroxylase isoenzyme 2, an enzyme modifying the basement membrane collagen IV. J Biol Chem 283:19432-19439

Tucker RP, McKay SE (1991) The expression of tenascin by neural crest cells and glia. Development 112:

Wagenseil JE, Mecham RP (2007) New insights into elastic fiber assembly. Birth Defects Res C Embryo Today 81:229-240

Wai AW, Ng LJ, Watanabe H, Yamada Y, Tam PP, Cheah KS (1998) Disrupted expression of matrix genes in the growth plate of the mouse cartilage matrix deficiency (cmd) mutant. Dev Genet 22:349-358 
Wang J, Ruan NJ, Qian L, Lei WL, Chen F, Luo ZG (2008a) Wnt/beta-catenin signaling suppresses Rapsyn expression and inhibits acetylcholine receptor clustering at the neuromuscular junction. J Biol Chem 283:21668-21675

Wang X, Harris RE, Bayston LJ, Ashe HL (2008b) Type IV collagens regulate BMP signalling in Drosophila. Nature 455:72-77

Wassarman PM, Jovine L, Litscher ES (2004) Mouse zona pellucida genes and glycoproteins. Cytogenet Genome Res 105:228-234

Watanabe H, Kimata K, Line S, Strong D, Gao LY, Kozak CA, Yamada Y (1994) Mouse cartilage matrix deficiency (cmd) caused by a 7 bp deletion in the aggrecan gene. Nat Genet 7:154-157

Watanabe H, Yamada Y (1999) Mice lacking link protein develop dwarfism and craniofacial abnormalities. Nat Genet 21:225-229

Wells RG, Discher DE (2008) Matrix elasticity, cytoskeletal tension, and TGF-beta: the insoluble and soluble meet. Sci Signal 1:e13

Wenstrup RJ, Florer JB, Davidson JM, Phillips CL, Pfeiffer BJ, Menezes DW, Chervoneva I, Birk DE (2006) Murine model of the Ehlers-Danlos syndrome. col5a1 haploinsufficiency disrupts collagen fibril assembly at multiple stages. J Biol Chem 281:1288812895

Whitelock JM, Melrose J, Iozzo RV (2008) Diverse cell signaling events modulated by perlecan. Biochemistry 47:11174-11183

Yamamoto S, Fukumoto E, Yoshizaki K, Iwamoto T, Yamada A, Tanaka K, Suzuki H, Aizawa S, Arakaki M, Yuasa K, Oka K, Chai Y, Nonaka K, Fukumoto S (2008) Platelet-derived growth factor receptor regulates salivary gland morphogenesis via fibroblast growth factor expression. J Biol Chem 283:23139-23149

Yao Y, Nowak S, Yochelis A, Garfinkel A, Bostrom KI (2007) Matrix GLA protein, an inhibitory morphogen in pulmonary vascular development. J Biol Chem 282:30131-30142

Yao Y, Shahbazian A, Bostrom KI (2008) Proline and gamma-carboxylated glutamate residues in matrix Gla protein are critical for binding of bone morphogenetic protein-4. Circ Res 102:1065-1074

Yao Y, Zebboudj AF, Shao E, Perez M, Bostrom K (2006) Regulation of bone morphogenetic protein-4 by matrix GLA protein in vascular endothelial cells involves activin-like kinase receptor 1. J Biol Chem 281:33921-33930 
Yoon BS, Ovchinnikov DA, Yoshii I, Mishina Y, Behringer RR, Lyons KM (2005) Bmprla and Bmprlb have overlapping functions and are essential for chondrogenesis in vivo. Proc Natl Acad Sci U S A 102:5062-5067

Yu J, McMahon AP, Valerius MT (2004) Recent genetic studies of mouse kidney development. Curr Opin Genet Dev 14:550-557

Yu WM, Feltri ML, Wrabetz L, Strickland S, Chen ZL (2005) Schwann cell-specific ablation of laminin gamma1 causes apoptosis and prevents proliferation. J Neurosci 25:4463-4472

Yurchenco PD, Amenta PS, Patton BL (2004) Basement membrane assembly, stability and activities observed through a developmental lens. Matrix Biol 22:521-538

Zakin L, Metzinger CA, Chang EY, Coffinier C, De Robertis EM (2008) Development of the vertebral morphogenetic field in the mouse: interactions between Crossveinless-2 and Twisted Gastrulation. Dev Biol 323:6-18

Zhu Y, Oganesian A, Keene DR, Sandell LJ (1999) Type IIA procollagen containing the cysteine-rich amino propeptide is deposited in the extracellular matrix of prechondrogenic tissue and binds to TGF-beta1 and BMP-2. J Cell Biol 144:1069-1080 
